\title{
MISERIA DE LA POESÍA (ENTRE LOS POETAS LATINOS)
}

BARTOLOME SEGURA RAMOS

Universidad de Sevilla

Que los versos, la poseía, no son nada, no producen nada y obligan al que los hace a morirse de hambre es algo sabido de siempre, y los poetas romanos más cínicos como Marcial o Juvenal así lo formulan, y desaconsejan a sus amigos que escriban poesía. Semejante situación se podría ilustrar ampliamente y en caso de ceñirse a unos pocos ejemplos habría para escoger casi libremente; sin embargo, prefiero elegir dos poetas ilustres de la época de Augusto, de quienes la conciencia poética es ideal y sublime, y otro de la época sórdida de Domiciano que en posición similar a los dos anteriores representa una manifestación diferente de la miseria de la poesía.

Horacio y Virgilio ilustran bien esta situación. Si bien el primero recapacita reiteradamente acerca del menester poético, nunca lo hace para denunciar la precariedad del poeta sino para censurar a quienes escriben mal poesía. Los dos, él y Virgilio, deben su bienestar a Augusto y sobre todo a Mecenas. Para la etapa del cruel tirano Domiciano, Estacio puede servir perfectamente de ejemplo.

Horacio dedica a Mecenas la primera composición de sus cuatro diferentes obras, a saber, el primer epodo, la primera sátira, la primera oda y la primera epístola; aparte de éstas, otras muchas composiciones tienen por destinatario al mismo; en concreto, salvo error u omisión, las referencias a Mecenas son: los epodos 1, 3, 9; las sátiras I 1, 3, 6 y alusiones en Sát. II 7 y 8; las odas I 1, 20; 
II 12, 17, 20; III 29; IV 11; las epístolas I 1, 7, 19. Habría que distinguir, empero, un Mecenas horaciano luminoso y señorial, al que el poeta no escatima elogios aun dentro de la atmósfera amistosa en que dicha relación de patrono y patrocinado se movió, patente en las Odas, comenzando por la primera (I 1), en la que Horacio afirma el carácter y papel de Mecenas en su vida: «Mecenas, originario de atávicos reyes/, protección mía y dulce ornato mío», y que repite cuasi verbatim en II 17: «Mecenas, gran ornato y cumbre de mi vida», ese protector al que invita cariñosamente en III 29, 1-4: «Mecenas, descendencia tirrena de reyes»; pues Mecenas es a través de las Odas dilecte, beate, care, y de él dirá en IV 11: Desde este día Mecenas mío ordena los años que corren, de la figura que se diseña en las Sátiras y Epístolas. En éstas en efecto Horacio se permite polemizar diríamos con su protector y paulatinamente dar muestras de rebeldía. Ya en la Sát. I 6 Horacio expone a Mecenas su tesis acerca de que la virtud es más importante que la nobleza de sangre aprovechando ciertamente según asevera el propio poeta la opinión en el mismo sentido de Mecenas, al cual vuelve a recordar su origen etrusco. Horacio evoca el día en que fue presentado a Mecenas, evoca la educación recibida de parte de su padre y en la Epístola I 1, 12-14 advierte: «Y para que no me pregunte acaso bajo qué guía, bajo qué lar me amparo/, no obligado a jurar en nombre de ningún maestro / dondequiera que me arrastran las circunstancias me dejo llevar de huésped». Y en la Epíst. I 7 el poeta reivindica aún más su independencia comenzando por narrar cómo había prometido a su benefactor volver a Roma y ha dejado pasar todo el mes de agosto ausente; añade que en septiembre es mal tiempo y que en invierno prefiere buscar el clima cálido de la costa; por fin, en primavera, con «los céfiros y la primera golondrina», regresará el poeta. Porque Mecenas no hace sus favores como el calabrés, que invita a comer higos afirmando que los que se coma el invitado quedarán para los cerdos; porque él, Horacio, antes que deber favores en estas condiciones está dispuesto a devolverlo todo.

Si Mecenas es después de todo un hombre que favorece a los poetas y por muchos halagos que el poeta le haga no deja de ser considerado un hombre, Augusto no es nunca un hombre, es más que eso en la poesía horaciana. Augusto es el guerrero invicto y acto seguido un dios, el dios que oficialmente llego a ser por resolución del Senado. En Odas IV 2, 33-36, Horacio asegura de un amigo que cantará con mayor plectro al César cuando arrastre a los sigambros por la costanilla sagrada; en IV 5, 25-27, dice el poeta: «¿Quién puede temer al parto, quién al helado escita?/, quién a los engendros que pare la escalofriante/ Germania si el César está sano y salvo?» Luego, ese ser victorioso se transforma naturalmente en divinidad. Ya en Odas I 2, 41-52, al final de una serie de dioses es César quien asoma sobre las tierras, es César al que se le ruega que tarde en volver al cielo; en IIl 14 Augusto es homologado a Hércules y 
así retorna victorioso de las riberas hispanas, y en versos 14-16 confiesa el poeta: «yo no temeré una revolución/ ni morir violentamente si el César/ manda en las tierras».

La IV 4 está dedicada fundamentalmente a Druso, hijastro de Augusto, y el poeta aprovecha para honrar a su augusto padre adoptivo (los enemigos podrán saber «qué vale el ánimo paternal de Augusto respecto de los niños Nerones -Druso y Tiberio-»); y la última oda de la colección íntegra (IV 15) dice (versos 4 ss.): «Tu edad, César/, ha devuelto a los campos los fértiles frutos/ y restituido a nuestro Júpiter las banderas/ arrancadas de las jambas arrogantes/ de los partos, ha cerrado el Jano Quirino/ vacío de guerras, ha puesto/ en orden correcto la libertad que escapaba/ a los frenos y removido las culpas/ y vuelto a traer las viejas artes/ por las que la nación latina y las fuerzas/ de Italia crecieron, y la fama y la dignidad/ del Imperio se han extendido hasta el orto/ del Sol desde su lecho occidental./ Guardián del poder el César, ni la locura/ civil ni la violencia alterarán la paz/ ni la ira, que forjo espadas/ y enemista a las míseras ciudades./ Ni los que beben en el Danubio profundo/ romperán los edictos julios, ni los Getas/, ni los Seres o los desleales Persas,/, ni los nacidos cabe el río Tanais./ Y nosotros en los días de vísperas y en los sacros/ en medio del don del jovial Líbero/ junto a nuestra prole y nuestras damas,/ rezando antes ritualmente a los dioses, / a los generales valerosos, como nuestros padres/ con canciones mezcladas por flautas lidias,/ a Troya y a Anquises y a la descendencial de Venus amamantadora cantaremos./».

En Virgilio, Augusto es un dios desde el primer momento, aunque también pasa por la fase de héroe grandioso. En Geórgicas III 46-47 afirma el poeta: "Luego empero me pondré a cantar las ardientes batallas/ del César y a llevar en boca de la fama su nombre por tantos años/ cuantos del primer origen de Titono dista el César.» Y en IV 2, 560-562, vemos a Augusto en camino de convertirse en dios (pero aún no es llamado Augusto, que en Virgilio sólo recibe este nombre en Eneida VIII 678): «Mientras el gran César fulmina/ con la guerra junto al profundo Eufrates y vencedor da/ leyes a pueblos que lo quieren, $y$ emprende el camino al Olimpo.» Pero la apoteosis de César la teníamos ya en Geórgicas I 24-42, donde tras una retahíla de dioses mayores y menores viene en invocación singular el César del que se espera que quiera ser dios del cielo, del mar o de la tierra, pero nunca del mundo subterráneo, y como tal dios se pide que asista a los campesinos a los que van dirigidas las Geórgicas. En Geórg. III 16, en medio de una ensoñación de futuro, Virgilio dice: in medio mihi Caesar erit templumque tenebit, y ya en la Egloga primera había sentenciado (610): «Un dios nos dio este ocio/ pues siempre aquél será para mí un dios; de él el altar/ a menudo un tierno cordero manchará de nuestro redil. El, como ves, 
permitió que mis vacas campeasen/ y que yo tocase lo que quisiera con el caramillo rústico.»

Las Geórgicas están dedicadas a Mecenas, que es nombrado en las cuatro, pero de tal manera que en la primera y en la cuarta sólo su nombre es puesto, en ambos casos en el segundo verso, y nada más se dice acerca del benefactor del poeta. En las otras dos, las centrales II y III, Virgilio dedica unos versos a Mecenas que resume cumplidamente sus sentimientos respecto de su protector; algunos términos recuerdan lo visto en Horacio, aunque el mantuano consigue sintetizar y transmitir más lapidariamente lo que pretende expresar. Primero, en Geórg. II 39-46, afirma el poeta: «Y tu ven aquí y a una acompaña la labor que emprendo/ oh ornato, oh con razón parte mayor de mi fama,/ Mecenas»; en III 40-42 dice: «Entretanto, sigamos las selvas y sotos intactos/ de las Dríadas, ordenes tuyas nada blandas, Mecenas:/ sin ti nada profundo inicia la mente.» Mecenas es más que protector, que lo es ciertamente, la musa que inspira al poeta; de esta forma, mientras César es el dios remoto y distante y por tanto inalcanzable para el simple mortal, Mecenas es sencillamente el hombre que es tratado como tal, pero con la singularidad que el agradecimiento del poeta le confiere.

La conciencia de la relación de supeditación del poeta a sus benefactores ya hemos visto en Horacio que existía y en alto grado; que dicha relación no tenía por qué ser humillante lo declara abiertamente el mismo Horacio en la Epístola II 1 dedicada al César, a quien se decide e enviar la epístola movido por los reproches del propio Augusto, según Donato, y de lo que parece ser prueba el comienzo precisamente: «Siendo así que sostienes solo tantos y tamaños asuntos,/ defender por las armas a la nación itálica, dotarla de moral/, proveerla de leyes, pecaría contra el bien común/ si demorase tu tiempo con larga diatriba, César.», al afirmar (ibídem, 245-247): «Mas no deshonran tus juicios sobre ellos ni/ los regalos que con mucha alabanza del que los da han tenido/ los amados por ti Virgilio y Vario poetas.» Digamos para finalizar con Horacio que las referencias a Augusto son: Epodo 9; Sát. II 1; Odas I 2; III 4, 5, 14, 25; IV 2, 5, 15; Epístolas II 1.

El autor que hemos elegido para ilustrar la relación miserable de la poesía con el poder en época postclásica es Estacio, que nació más o menos cuando Marcial y murió más o menos cuando Domiciano, a quien dedica varias de sus Silvas, en concreto I 1, 6; IV 1, 2, 3; y hay alusiones en V 1 vv. 76-107; 164; 190-192; 240-241. La primera de ellas lleva por título Equn maximus Domitiani $I M P$, y está dedicada a cantar la estatua ecuestre de este emperador en el foro romano. En dicha Silva vierte afirmaciones tan poco creíbles como que al caballo lo recomienda «el amable jinete;» y continúa aseverando que «es un placer contemplar/ un rostro donde se mezclan las marcas de la guerra y que com- 
porta la paz apacible». Y no olvidemos que está hablando de Domiciano. De modo que uno está tentado de interpretar las adulaciones del poeta en la misma línea que quiere hacerse con la dedicatoria de Lucano (poeta por cierto al que Domiciano dedica una Silva y al que profesa una gran admiración) al emperador Nerón, en cuyo honor afirma que, si era para que viniese al mundo un ser tan excelente como él, benditas sean las guerras civiles y la mucha sangre derramada. Pero en fin, Domiciano es según Estacio una «estrella» y «la propia forma presente del dios (Domiciano) coadyuva en las tareas (de fabricación del caballo de bronce)» Los versos 74-75 dicen: «Salve, descendencia y padre de grandes dioses/ divinidad de lejos oída por mí»; de sus ojos afirma que imitan «las llamas siderales», y termina la Silva así: «Sin dudarlo ama las tierras, y los templos que te dedicamos/ habítalos tú mismo; y no te agrade la corte celestial, y veas/ contento que tus nietos dan incienso a este regalo», de tal forma que desea a Domiciano lo mismo que Virgilio en Geórgica I 24 ss. a Augusto y que Horacio en Odas I 2, versos 44-52 al propio Augusto, a saber, que permanezca en las tierras y no vuelva al cielo sino muy tarde. De la misma manera en la Silva I 6, llamada Kalendae Decembres, el poeta narra un día de fiesta en que Domiciano da espectáculos al pueblo y hace numerosos regalos. Ahora el emperador es directamente convertido en Júpiter (25-27): «Guíe Júpiter las nubes por el orbe/ y amenace lluvias para los anchos campos/ con tal de que éstos sean los chubascos de nuestro Júpiter». En la misma línea de exagerada adulación se inscribe la Silva IV 1, Septimus decimus consulatus Imp. Aug. Germanici; y la IV 3 tiene un tema curioso, pues se trata de la construcción de una calzada, la Via Domitiana, que iba desde Minturnas, separándose de la Via Appia hasta Pozzuoli, un tramo de la costa cubierto de marismas y pésimo para el comercio, razón por la que se acometió dicha construcción. Al poeta le inspira cosas como las palabras del río Volturno dirigidas a Domiciano (72-94) o las palabras de la Sibila de Cumas (124-163); cf. 128-129: «Helo, aquí está el dios, a éste manda Júpiter/ que impere en su nombre sobre las tierras»; y en $139 \mathrm{di}$ ce: «Salve, caudillo de hombres y padre de dioses». Por último en IV 2, Eucharisticon ad $\mathrm{Im}$. Aug. Germ. Domitianum, canta el poeta: «El banquete regio de la sidonia Elisa alaba/ quien llevó al gran Eneas a los campos laurentes; y los manjares de Alcínoo en poema duradero declara/ quien a Ulises al volver en muchos mares desgastó:/ más yo, a quien el César concedió insólito gozo de sagrado almuerzo/ por vez primera ahora, y no levantarme de señorial mesa,/ ¿con qué lira celebro mis anhelos; qué gracias estoy/ en condiciones de dar? Aunque Esmirna y Mantua aunasen/ por parejo laureles perfumados en mi testa feliz/ no diría cosa digna./ ¡En medio de las estrellas me parece/ estar sentado con Júpiter y tomar con diestra troyana el vino/ inmortal que me sirven! Años estériles hemos pasado:/ éste es el primer día de mi edad; aquí esta el umbral 
de mi vidal. ¿A ti te veo yo echado, monarca de las tierras/y gran padre del orbe sometido; a ti, esperanza de los hombres;/ a ti, cuita de los dioses? ¿Cábeme mirar de cerca tu cara/ entre mesas y copas de vino, y es lícito que no me levante?» A continuación el poeta describe el palacio de Domiciano, y afirma que es al emperador a quien más ansía mirar; y lo compara sucesivamente con Marte Gradivo, Pólux, Baco y Hércules, hasta terminar comparándolo con Júpiter. Al final del poema le desea larga vida y recuerda que en los Juegos Albanos el poeta ha ganado un premio con un poema sobre las campañas germánicas y dácicas de Domiciano.

Como apuntamos al comienzo, la nómina de poetas que han servido al señor o adulado al poderoso para poder comer de su poesía se haría inacabable, aún sin salirnos de la poesía romana. Adviértase pues cómo la poesía no era en Roma libre tampoco, compruébese cómo los textos que tenemos nacieron con frecuencia del vilipendio y la humillación, aun cuando algunos supieron conservar la dignidad y otros, llevados por los tiempos, la perdieron casi por completo. La poesía sin embargo se ha vengado: ha perdurado, negando a menudo la miseria de donde nació. 